\title{
Developing the Inclusive Course Design Tool: a tool to support staff reflection on their inclusive practice
}

\author{
Susan V Smith, Ruth Pickford, Janice Priestley, Rebecca Sellers \\ Centre for Learning \& Teaching, Leeds Beckett University, UK
}

\begin{abstract}
Inclusivity is fundamental to higher education, its course design, its assessment and its delivery. The principles of inclusivity offer all students the opportunities to achieve to the best of their ability. The purpose of this case-study is to outline the context, process, development and initial evaluation of a newly generated tool designed for academic colleagues. The Inclusive Course Design Tool (ICDT) offers a series of questions for reflection with supporting guidance rooted in theory and research on inclusion, pedagogy, multiculturalism, universal design for learning and implicit and unconscious bias. This first version of the tool encourages course teams to reflect on and interrogate the nature of inclusive academic practice in their courses, in their course curricula, their classrooms (virtual or physical) and their approaches to student learning and support. The contextualised rationale for the tool, its design, the consultation process, its early evaluation and future considerations as an institutional tool are explored. This paper specifically explores its use to try to reduce the black, asian and minority ethnic (BAME) student award gap and enhance success and graduate outcomes, as well as academic practice and staff reflection.
\end{abstract}

\section{Introduction}

A project team in The Centre for Learning \& Teaching generated The Inclusive Course Design Tool as part of our institutional Access and Participation Plan (APP) activity, particularly, at first, to help to address our BAME student award gap and also to address and support the Office for Students' (2019) drive for wider excellent inclusive practice. It is one strand of a range of initiatives to catalyse Leeds Beckett University to fulfil its key performance indicators for student continuation, satisfaction and success and to generate impetus in improving our inclusive practice specifically at course level to support all our diverse student groups and to improve the equality of opportunity for under-represented groups to access higher education (HE) and to progress and succeed in it.

The inclusive design and delivery of teaching, learning and assessment methods that allow all students to engage meaningfully with the curriculum and achieve their full potential is fundamental to good course design (Thomas and May, 2010) and the project team felt that 'the course' - its curriculum, syllabus and design - was the place to concentrate colleagues' energies. The tool was born of many institutional and sector contextual and practical pressures and a strong feeling that we needed a simple 'one-stop device' which would enable staff to scrutinise the design and detail of their courses through a diversity and inclusion lens.

The tool was intended to catalyse the course teams to reflect on and interrogate their course-level inclusive design and practice. It was to be used once for each individual course at the design phase and thereafter as an enhancement tool. We wanted the outcome of our 
collaborative work to promote ownership of subject-specific inclusive practice and catalyse actions for enhancement through deep reflection, not just a superficial 'ticking off' of perceived activity. A pure 'checklist' approach would not have fostered in educators this deep reflection (De la Croix and Veen, 2018) and colleagues' feedback showed something better designed, likely to promote reflection, interrogatory and yet administratively 'light' would encourage more ownership and colleague engagement.

\section{Our different diverse student groups}

There was a clear need to consider the inclusive learning experience of and best practice for different student groups and their intersectionality had become a priority. In addition, we had to address a closing of our BAME student award gap while also respecting the specific needs of all our diverse student groupings: for example, our international students, those with mental health needs, disabled students, those from a disadvantaged socio-economic background, students who commute, estranged students or those who may be entering university from care.

For 2019-20, however, the reducing of the BAME student award gap needed close attention to catalyse more rapid change and improvement. In 2020, $19.2 \%$ of our students are BAME (Leeds Beckett University, 2020) and our gap has been slowly closing with a downward trend over the past three years from 2016 , reducing from $20.7 \%$ to $14.4 \%$. The University had already made a range of clear, evidence-based strategic actions to address this - such as projects to research BAME students' lived experience (Smith, 2017), focused activity relating to placement access, inclusive practice resources and webpages, enhanced practice guidance (Centre for Learning and Teaching, 2018; 2019), exploration and enhancement of course entry routes and the decolonising of curricular content and reading lists - but institutional results were patchy. The tool was 'invented' 1) to combine a full consideration of the evidenced factors which have impact on student achievement, with a nuanced understanding of course-specific pedagogy; 2) to allow staff to consider, specifically, the highlighting and enhancement of BAME students' experience.

\section{Contextual literature}

The tool questions needed to be rooted in best practice research. A literature review explored the key factors which impact on student satisfaction in higher education, student success and inclusive academic practice. The tool project team synthesised the findings and distilled them into the early drafts of the tool questions. The project team explored literature about intercultural education (Salkind, 2008; HEA, 2014; Advance HE, 2013; Sian, 2017), ethnicity and attainment (Cotton et al., 2013; Stevenson, 2012; Smith, 2018; Miller, 2016; Hoffmann et al., 2002) and students' sense of belonging (Ahn and Davis, 2019; Hausmann et al., 2007; Woodyat and Brooker, 2019; Tovar, 2013) to give context to the key issues. Then, literature relating to teaching excellence (Pickford, 2018; Palmer et al., 2014), cocreation of curricula (Bovill et al., 2016) inclusive feedback (Thomas and Jones, 2017;) placement practice (Jones et al., 2017) and institutional racism and microaggressions (Sue et al., 2007; Pilkington, 2013) was used to identify best practice. For local and applied context, academic colleagues and our BAME student ambassadors discussed our own recent institutional projects into our BAME student award gap, the needs of commuting 
students (disproportionately represented in BAME students) (Smith, 2017; 2018) and hopes for the future of the education of all our students.

\section{Main aims of the ICDT}

The tool was primarily developed to:

a) encourage colleagues, through active reflection stemming from using the tool, to be more focused in their appreciation of inclusive practice as core to their design of new courses and integral to the content and approach of existing courses;

b) underpin the 'signing- off' for quality purposes (by school senior leadership teams) of the linked tool action plans;

c) focus colleagues' attention on considering the factors which impact on student success and narrowing the award gap for BAME students. The flagged questions are designed to help with this;

d) embed basic standards of inclusive practice for all, thereby enabling a review of the current reasonable adjustment process;

e) increase the visibility of specific groups of students through the wording of the questions and the language and terms used;

f) ensure accessibility. Under the Equality Act (2010), we are required to ensure that all our services and materials are accessible to disabled students. As such, it is necessary to ensure that all teaching and learning environments can be accessed and used by any disabled student, not only those students who choose to tell us they have a disability. We used the JAWS (Job Access With Speech) accessibility test to assess the accessibility of features used in the tool on Android and ios devices;

g) be suitable for teams of course staff to use online or face to face or on blended courses. This was especially pertinent with changing ways of practice during and after the coronavirus pandemic. Equally, the language used in the tool needed to relate to the diverse ways we deliver courses (i.e. wholly online, blended and face to face).

Alongside the literature review of current contextual research, we undertook a scoping of other course-focused inclusive practice resources in the sector, reviewing their accessibility, quality, breadth, practicality and supporting guidance (MMU, 2020; SOAS, 2018; UCL, 2018).

Most of these resources, though valuable, adopt a checklist approach or one that focuses on specifics and less on the adoption of a coherent holistic approach to good course design, delivery and pedagogy. Our approach acknowledges the philosophy of the 'Connected Curriculum' (Fung, 2017) which advocates that students should learn actively through research and critical enquiry, rather than by passively receiving accepted knowledge. It also reflects Croucher and Roman's (2007) work, which affirms that inclusive course design 
acknowledges all students' entitlement to access a course and to participate in it and advocates consideration of this entitlement through all elements of a course life cycle. We also acknowledge that students are individuals and learn in different ways and that a nonfragmented, coherent and inclusive course design lends itself to simpler teaching, is easier to plan, is easier and more meaningful for all students to understand and generates better student outcomes (HEA, 2011; Hockings, 2010). Although Moore et al. (2017) have devised a reflective tool for United States (US) universities which considers inclusion, this primarily addresses broader social issues (e.g. unconscious bias, multicultural education and the hidden curriculum) and has less emphasis on specific reflection upon the practical and pedagogic course-related issues. Our ICDT uniquely focuses on six elements (Pickford, 2018) which, when synthesised, enhances the coherence of the design but also offers the opportunity for colleagues to reflect on the specific needs and style of their course and how to improve its pedagogy and practical delivery.

\section{Key features of the ICDT}

The key features and approach to implementation are:

a) We mapped and considered our institutional APP requirements as part of conceptualisation and design of the tool. The tool itself (and its questions for reflection) is designed around the philosophy that student success is dependent upon individual student engagement and that engagement is an individually-owned and personal concept (Saks, 2006). Our methodology builds on this philosophy by explicitly specifying the requirements for maximising student engagement in a course (table 1, Pickford, 2016). The tool specifically focuses course team reflection on curriculum design, the learning environment and different learning activities.

\section{Table 1: Inclusive course-level design.}

\begin{tabular}{|l|l|l|}
\hline $\begin{array}{l}\text { Requires opportunities for all } \\
\text { students individually to } \\
\text { engage with their course: }\end{array}$ & $\begin{array}{l}\text { Can be provided only } \\
\text { through design of a } \\
\text { course's: }\end{array}$ & $\begin{array}{l}\text { Is achieved through } \\
\text { course-level: }\end{array}$ \\
\hline behaviourally & curriculum & \\
\cline { 2 - 3 } & learning environment & planning \\
\cline { 3 - 3 } & learning activities & management \\
\cline { 3 - 3 } emotionally & & student support \\
\cline { 2 - 3 } & community \\
\hline conceptually & student development \\
\hline
\end{tabular}

These six best practice core sections which structure the format of the tool (see figures 1a-1f below) are consequently 1.) planning your course, 2.) managing your course, 3.) supporting all students on the course, 4.) building the course community, 5.) providing appropriate development opportunities for all students and 6.) challenging all students on the course. Institutional priorities (for satisfaction, continuation and student outcomes) and requirements for the United Kingdom (UK) Quality Code for HE and Framework for Higher Education Qualifications (FHEQ) requirements and outcomes are encapsulated in its content (Pickford, 2018). It has underpinned approaches to course development at Leeds Beckett University since 
2016 and has been evaluated and tested in use at an institutional level as well as having informed practice across the sector. Its perceived quality has led to requests to use it from other higher education institutions (HEls). The tool's questions are all underpinned by research evidence and a full, linked TALIS Aspire reading list is integrated into each of its sections. Each segment of it has tailored resources and simple, jargon free, contextual guidance.

b) We developed contextual guidance which was then reviewed through several iterations by colleagues for relevance and understanding. We also asked them to offer their own discipline-specific literature on inclusive practice to inform the research base and we integrated suggestions into the reading list.

c) Our internal Centre for Learning and Teaching (CLT) Teach Learn page hosts the tool and its guidance, with supporting text for colleagues. We intend to make it available to the sector through open access and we'll consider licensing it to Creative Commons after it has been fully evaluated on completion of two academic cycles.

d) We established face-to-face and online webinars for staff development across both campuses to support colleagues to use the tool.

e) All course teams were expected to use the tool from March 2020 (after its approval by the University Academic Board) to explore their inclusive practice in both the design and delivery of their courses.

f) Course directors were expected, by summer 2020, to formulate an initial action plan, which in the first year focuses specifically on the thirteen flagged specific BAME attainment / experience-related questions. (see figures 1a-1f). In practice, some of this activity was unfortunately delayed and patchy due to pandemic related priorities.

g) Action plan implementation is to be undertaken as part of the course monitoring annual review and enhancement processes and reported on through our Academic Quality and Standards Committee.

h) From 2020/21, the tool must be used to inform all new course validations. Our University deans will then need to sign off the use of the tool and its new coursedesign action plan prior to the granting of new course approval.

\section{The development process:}

We gradually refined the tool through four consultative phases from an initial booklet with seventy-three questions to a forty-two-question graphical form with eighty-five unique, supporting, evidence-based resources. We sought wide consultation over several months from academic and professional service staff, the Students' Union and their representatives prior to formal University approval.

This iterative development process revealed the need to consider inclusive practice at course, rather than module level. Colleagues felt that a more holistic reflection would offer a more integrated, coherent view of activity, identify gaps and reduce silo working. Staff felt that there was then potential for an individual module review of inclusive practice, to follow 
once the gaps and concerns had first been identified and discussed collaboratively at course level.

The feedback from colleagues and students mainly focused on the need for: plain English; more flagging and increased visibility of the questions which targeted BAME students' learning experiences specifically; more rigorous accessibility software checking; ease of use (hard printed copy or online completion across all formats and platforms); and tighter, clearer, research-based guidance recommendations. A sign-off sheet for senior managers was also requested and this was included into the tool.

\section{The tool questions:}

\section{The Inclusive Course Design Tool}

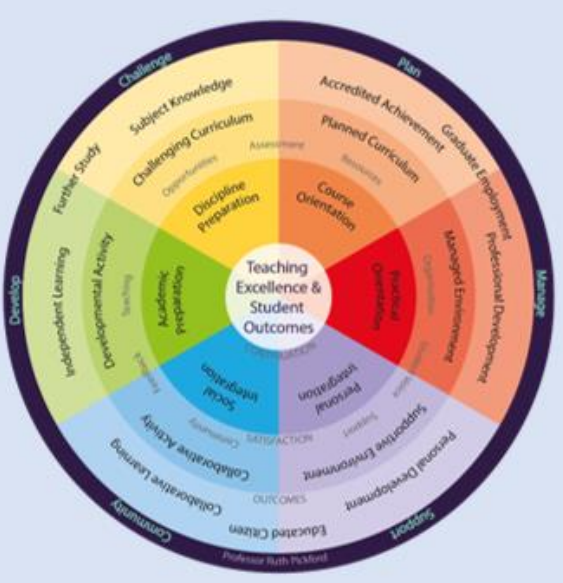




\section{The Inclusive Course Design Tool}

Introduction

Who is this Tool for? All colleagues involved with the design and delivery of our courses.

What and When: The Inclusive Course Design Tool can be used to help teams reflect and focus on the design and delivery of high quality, inclusive UG and PG courses at LBU.

Course teams should consider the questions listed here as a way of interrogating and reflecting on their practice prior to new course approval or as a reflective tool as part of ongoing course enhancement.

The structure: This Tool is structured in six parts - planning your course, managing your course, supporting all students on the course, building the course community, developing all students on the course, challenging all students on the course (Pickford, 2018). It will take around an hour to complete.

The context: Consideration of all our diverse student groups* and how to maximise their learning and attainment is fundamental to course design and delivery and we must enable all students to be satisfied with their learning experience and progress to complete their study with a positive outcome.

Institutional priorities (for satisfaction, continuation and graduate employment) and requirements for the UK Quality Code for $\mathrm{HE}$, our institutional APP and FHEQ requirements and outcomes are encapsulated in the Tool's reflective questions.

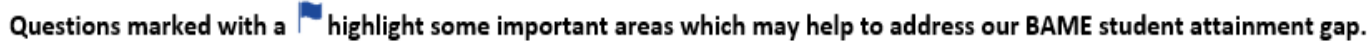

Resources and guidance to help you answer each question are in a Talis reading list, links to which can be found at the end of the document. You may identify, after using the Tool, that your team needs further support with some questions. If so, please contact clt@leedsbeckett.ac.uk for further signposting and help.

Submit the completed document as an Appendix with your course validation documentation.

* Particularly, black, Asian, international students and those with mental health needs, disabled students, those who may be first in their family to enter $\mathrm{HE}$, those from a disadvantaged socio-economic background, students who commute or are carers, estranged students or those entering $\mathrm{HE}$ from care. Intersectionality of these student groups should also be considered.

This guidance is produced by the Centre for Learning and Teaching

February 2020

\section{Figure 1. Inclusive Course Design Tool}

The tool's questions are detailed below in the shaded sections (sections 1a-1f). The questions marked with a po highlight some important areas which, based on the literature, may help to address our BAME student award gap.

Some questions were piloted and rephrased many times during the consultation process to ensure clarity. Simple supplementary research-based explanations (to explain the rationale of each question) were inserted in the linked guidance. Academic colleagues do, as part of the nature of their role, take a critical and interrogatory approach to information. This was regarded as important during the writing of the questions and the supporting tool guidance. Ambiguities in wording which led to staff confusion were taken seriously. For example, during consultation, staff discussed their understanding of inclusive terminology and using inclusive images in relation to question 1.8 - "Do your course and module materials and handbooks use appropriate plain, inclusive terminology, language and images?"

The insertion of specific supporting references to enhance clarification, guidance from the Plain English campaign about inclusive language and the statement "Simple jargon-free language allows more students to engage more easily with materials "helped clarify understanding about the question for colleagues. Each question was systematically explained and addressed in this way. 


\section{PLANNING YOUR COURSE}

1.1 Have you included a clear course statement related to inclusive programme values within your student-facing course documents?

1.2 Do your course aims and the overarching course design consider your students' diverse prior learning experiences (especially those who may be from underrepresented groups)? po

1.3 Does planning for the first term include taking active steps to understand the subject and broader academic/life experiences for all groups of incoming students?

1.4 Do you identify in advance, specific groups of students who may need additional support at pre-arrival, during induction or at course transition points?

1.5 Do you offer a choice of different assessment methods/tasks/topics to reduce the need for alternative assessments and is this choice clearly embedded in the module design and course assessment strategy?

1.6 Is there a clear course process for considering the clarity of assessment tasks and marking criteria?

1.7 Are your assessment submission dates planned using cultural calendars to ensure you are responsive to the religious and cultural needs of a diverse cohort?

1.8 Do your course and module materials and handbooks use appropriate plain, inclusive terminology, language and images?

1.9 Does the course team provide students with electronic copies of teaching materials developed and produced in accordance with UK accessibility guidance?

1.10 Do you specifically consider how to integrate commuting students into the course? (e.g. consideration of social space, careful timetabling, blended learning, assessment submission timing) bu

\section{Figure 1a. Questions for planning your course}

\section{MANAGING YOUR COURSE}

2.1 Does your course monitor the number of applications received from different groups of students and actively seek to address any differences?

2.2 Do your interview (if applicable) and selection processes support all groups of applicants equally?

2.3 Are students made aware of all potential additional costs and equipment pre-entry?

2.4 Does your course have a consistent language and structure across its online spaces that students can easily navigate?

2.5 Do you record lectures/sessions? Do you have an agreed, documented course guidance on sharing recordings?

2.6 Do you have strategies in place to understand and share feedback on the experiences of all students (especially those from under-represented groups)? pu

Figure 1b. Questions for managing your course 
SUPPORTING THE STUDENTS ON THE COURSE

3.1 Do you have access to the individual profiles and support requirements of all students?

3.2 Do you have a clear process for each student to have a named Academic Advisor (AA)?

3.3 Do you have any course AA projects/schemes that target specific groups of students? pu

3.4 Do you have library induction/study skills/diagnostic learning timetabled into induction and the early part of the course?

3.5 Do you provide online/face-to-face opportunities for all students to share their diverse experiences (especially those who may be from under-represented groups) very early in the course? po

3.6 Do you offer formative bite-size assessment opportunities early in the course, so students have an opportunity to 'fail safely' and seek support?

3.7 Do you run defined sessions for students who may have failed elements of their assessments? (e.g. structured summer support, revision sessions etc.)?

3.8 Do you have a clear course communications process to promote engagement at critical times for all your students (pre-arrival, post-Christmas, first assessment period, during exams, study abroad, during off-campus placement)?

3.9 Is space and time given in some teaching sessions and office hours for students to openly acknowledge and discuss racist or racialising behaviours? pu

3.10 Do your students have opportunities and a place to go to discuss racist or racialising behaviours which have impacted on them? py

Figure 1c. Questions on supporting the students on the course

\section{BUILDING THE COURSE COMMUNITY}

4.1 Does the programme explicitly plan activities that nurture a culture of academic belonging from the beginning? to

4.2 Does the course explicitly foster a culture of social belonging at all levels?

4.3 Do you co-create or seek feedback from students on the planned course timetable and consider its potential to disadvantage certain groups?

4.4 Do in-class and online learning activities promote inclusion and expose students to a range of views, opinions and cultural contexts? po

4.5 Do your course reading lists and resources offer a lens representative of a diverse population by including black and people of colour (BPOC), indigenous scholars and other authors with different cultural viewpoints? pu

4.6 Are your course materials and learning resources available electronically to support parity of access for distance, commuting, print-impaired students?

4.7 Does the way you allocate students to group work activities enable the creation of ethnically diverse groups from different educational backgrounds? pe

Figure 1d. Questions on building the course community 


\section{DEVELOPING ALL THE STUDENTS ON THE COURSE}

5.1 Are there safe, well-managed, interactive, virtual and physical classroom opportunities for all students to develop critical thinking and debate on issues relating to race, gender, global, social and cultural issues? po

5.2 Are there planned opportunities in the curriculum/course design and delivery for all students to co-create some elements of course activity if they wish?

5.3 Are there explicit, embedded and accessible opportunities for all students (especially those in under-represented or vulnerable groups) to access and benefit from qualityand-equality-checked placements, paid internships and preparation for graduate employability?

5.4 Are academic skills integrated into the course, preparing students to take control of their further development?

5.5 Do you vary the session type to allow for all different types of learners and could any of these inadvertently exclude particular groups of students?

\section{Figure 1e. Questions on developing all the students on the course}

\section{CHALLENGING ALL THE STUDENTS ON THE COURSE}

6.1 Does the course team have a way of identifying students who may be struggling with academic content?

6.2 Likewise, does the course team have clear practice in identifying talent and supporting those who need more stimulation and challenge?

6.3 Does the course use a range of differentiated activities and reading to support and challenge diverse cohorts?

6.4 Are the module assessment methods across each level of the course designed to enable all students to perform to the best of their ability?

Figure 1f. Questions on challenging all the students on the course

\section{Evaluation}

The tool's webpage has a feedback box, through which updates are continuously made in response to the users. The tool was being used by all our courses as mandatory in 2019-20 (161 undergraduate and 189 postgraduate courses). The Covid-19 emergency stalled initial completion by some of our courses, but all must complete and report on it as part of the 2020-21 academic quality cycle. Use of the tool will be fully evaluated after one academic cycle. An online survey and a focus group of a selection of academic course teams will explore: the quality of reflective discussions that were undertaken in the course teams; any changes made; the ease of use of the tool; its value and practicality and recommendations for future amendments. Module-level reflection will be encouraged once the initial course level gaps have been identified.

In parallel, we shall undertake some thematic qualitative analysis (Braun and Clark, 2013) of the action plans and enhancement reports to elicit innovative actions and practice themes which can be shared as best practice. We will also explore, as a specific measure, changes in course BAME attainment gaps, student satisfaction and retention rates as part of our continuous quality monitoring. 
In the meantime, interim feedback has been sought from internal users by email. Users have welcomed the tool and appreciate the wide consultation which has informed its design. It is regarded as "very assertive, which many other inclusive initiatives lack". The flagged questions highlighting the focus on issues underpinning the BAME students' award and success gap have been praised for their focus. We will undertake a full evaluation and further cycle of amendments in time which will illuminate further staff thoughts on the tool. Early feedback is positive, especially in relation to the rooting of the questions in research, the simplicity of the guidance and language and the ability for course teams to discuss their own course needs in relation to consideration of their own course student demographics and teaching approach. The general nature of the questions means that solutions can be found that best suit the academic style of the students and the discipline being taught. For example, courses in our Business School, which had lower numbers of students accessing placements and internships (question 5.3), are working on a new project with the Careers staff to address this. Other courses, for example in Health and Social Care, that have no issue with placement access, have developed more focus on considering how students are allocated to groups (after question 4.7 generated practice gaps). The perception that "thankfully, this is not a one-size-fits-all approach" appears to be an emergent factor in colleagues' willingness to use the tool. Staff have used it to complement the institutional drive to improve our student retention and our graduate outcomes - which has been a cause for concern, with our institution reported to have fallen $15 \%$ behind the UK average of $80 \%$ for graduate jobs. In 2017, the gap between our performance and the national average, was $15 \%$. This has now narrowed to $5 \%$.

\section{Future considerations}

The tool is comprehensive and its aims and purpose and the innate complexity of enhancing inclusive practice will continue to make it a work in progress. It is just one part of a huge initiative the institution has taken, gradually to improve the outcomes of our students. There is more to be done to push the scores up.

Practising what we preach, we feel such an inclusion tool should be inclusive itself and thus we want it to available, as soon as it is refined after the next cycle to a broader network of educators to grow its visibility and effectiveness. We have already facilitated deeper conversations about inclusion and diversity in our university.

A follow-up activity which encourages teams to review their module practice and to focus on questions in the 'Supporting' (figure 1c), 'Building Community' (figure 1d), 'Developing' (figure 1e) and 'Challenging' (figure 1f) sections of the tool will be undertaken if the courselevel reflection identifies gaps in practice which could usefully be ironed out at a more granular level.

Some staff feel that their awareness of diversity issues, raised through reflection on the questions has improved and changed their practice. Discussion with staff during and after early use of the tool and as part of the institutional drive to raise highly skilled graduate employment rates led to new initiatives for their student groups. These included planning a new BAME student mentoring scheme, improved detailed guidance and academic advisor practical staff training focused on supporting all diverse student groups. Institutionally, the funding of more mock assessment centres and student visits to employers are being 
considered; such developments will form part of the institution's access and participation work and equality and diversity activity.

Recent world events have also led to discussions about wider black inclusion issues at our university. The tool - particularly the questions on racialised behaviour (questions 3.9 and 3.10), social belonging (question 4.2) and reading and resource lists (question 4.5) - have helped course teams understand that $\mathrm{HE}$ is not immune from racism and they must strive to address the persistent inequalities in students' access, participation and experience. This discussion is helping to raise awareness and bring about action through wider initiatives, such as our Zero Tolerance campaign, plans for contextual offers, hardship funding and our progress towards better outcomes reported through our APP narrative.

Close attention to the inclusivity of just one course, generated by a course team that takes the needs of all the diverse groups of students seriously and diligently, may well improve that one course over time, but one course alone will not be sufficient to meet the needs of a whole university and enhance its overall attainment and experience data. It is therefore important that the tool continues to be promoted via a coherent two-pronged approach both as an institutional, strategic, contextualised directive and as a tool for course-specific, action-focused reflection and enhancement. In the meantime, the tool is for use by others and we shall seek - and much appreciate - feedback about its use, clarity and value in the wider HE sector.

\section{Reference list}

Advance HE (2013) 'Engaging Home and International Students: A Guide for New Lecturers.' Available at: https://www.advance-he.ac.uk/knowledge-hub/engaging-home-andinternational-students-guide-new-lecturers (Accessed: 29 April 2020).

Ahn, M.Y. and Davis, H.H. (2019) 'Four Domains of Students' Sense of Belonging to University.' Studies in Higher Education, January 1-13. Available at: https://doi.org/10.1080/03075079.2018.1564902 (Accessed: 29 Apr 2020).

Bovill, C., Cook-Sather, A., Felten, P., Millard, L. and Moore-Cherry, N. (2016) 'Addressing potential challenges in co-creating learning and teaching: overcoming resistance, navigating institutional norms and ensuring inclusivity in student-staff partnerships.' Higher Education, 71(2), 195-208. Available at: http://dx.doi.org/10.1007/s10734-015-9896-4 (Accessed: 29 Apr 2020).

Braun, V. and Clarke, V. (2013) Successful Qualitative Research: A Practical Guide for Beginners. London: Sage. ISBN: 9781847875815.

Cotton, D., George, R. and Joyner, M. (2013) 'The Gender and Ethnicity Attainment Gap Research Project.' Pedagogic Research Institute and Observatory (PedRIO). Available at: https://www.plymouth.ac.uk/uploads/production/document/path/5/5853/PedRIO Paper 2.pdf (Accessed: 29 April 2020).

Croucher, K. and Romer, W. (2007) 'Inclusivity in Teaching Practice and the Curriculum.' Guides for Teaching and Learning in Archaeology, 6. Liverpool: Higher Education Academy. 
Available at:

https://www.heacademy.ac.uk/system/files/Number6 Teaching and Learning Guide Inclus ivity.pdf (Accessed: 24 April 2020).

De la Croix, A. and Veen, M. (2018) 'The reflective zombie: Problematizing the conceptual framework of reflection in medical education.' Perspectives on Medical Education, 7, 394400. Available at: https://doi.org/10.1007/s40037-018-0479-9 (Accessed: 29 April 2020).

Fung, D. (2017) A Connected Curriculum for Higher Education. London: UCL Press. ISBN: 978-1911576341.

Hausmann, L.R.M., Schofield, J.W. and Woods, R.L. (2007) 'Sense of Belonging as a Predictor of Intentions to Persist Among African American and White First-Year College Students.' Research in Higher Education, 48(7), 803-839. Available at:

https://link.springer.com/article/10.1007/s11162-007-9052-9 (Accessed: 29 April 2020).

Higher Education Academy (2011) 'Inclusive curriculum design in higher education.

Considerations for effective practice across and within subject areas.' Available at:

https://s3.eu-west-2.amazonaws.com/assets.creode.advancehe-documentmanager/documents/hea/private/resources/introduction and overview 1568037036.pdf (Accessed: 30 May 2020).

Higher Education Academy (2014) 'Induction as Part of the Teaching International Students Project.' Report. Available at: https://s3.eu-west-

2.amazonaws.com/assets.creode.advancehe-documentmanager/documents/hea/private/resources/induction 1568037224.pdf (Accessed: 29 April 2020).

Hockings, C. (2010) 'Inclusive learning and teaching in higher education: a synthesis of research.' Available at: https://www.advance-he.ac.uk/knowledge-hub/inclusive-learningand-teaching-higher-education-synthesis-research (Accessed: 30 May 2020).

Hoffman, M., Richmond, J., Morrow, J. and Salomone, K. (2002) 'Investigating "Sense of Belonging" in First-Year College Students.' Journal of College Student Retention: Research, Theory \& Practice, 4(3), 227-256. Available at: https://doi.org/10.2190/DRYC-CXQ9-JQ8VHT4V (Accessed: 30 April 2020).

JAWS accessibility test. Available at:

https://www.freedomscientific.com/products/software/jaws/ (Accessed: 29 April 2020).

Jones, C.M., Green, J P. and Higson, H.E. (2017) 'Do Work Placements Improve Final Year Academic Performance or Do High-Calibre Students Choose to Do Work Placements?'

Studies in Higher Education, 42(6) June, 976-992. Available at:

https://www.tandfonline.com/doi/full/10.1080/03075079.2015.1073249 (Accessed: 30 April 2020).

Leeds Beckett University (2020) First degree honours - Five-year degree classification explorer 2014/15 to 2018/19. Leeds Beckett University internal data report: unpublished. 
Manchester Metropolitan University (MMU) (2020) The Inclusive Curriculum Toolkit. Manchester: Manchester Metropolitan University. Available at:

https://www.celt.mmu.ac.uk/inclusion/toolkit.php (Accessed: 22 April 2020).

Miller, M. (2016) 'The Ethnicity Attainment Gap: Literature Review.' The University of Sheffield: Widening Participation Research and Evaluation Unit. Available at:

https://www.sheffield.ac.uk/polopoly fs/1.661523!/file/BME Attainment Gap Literature Revi ew EXTERNAL - Miriam Miller.pdf (Accessed: 29 April 2020).

Moore, C., Brantmeir, E. and Brookfield, A. (2017) 'Inclusion by Design: Tool helps Faculty examine their teaching practice,' Higher Education Teaching and Learning, Faculty Focus.

Available at: https://sites.evergreen.edu/ltc/wp-content/uploads/sites/440/2019/09/Inclusionby-Design-Syllabus-Tool.pdf (Accessed: 30 June 2020).

Office for Students (2019) 'Access and Participation Plans.' Available at:

https://www.officeforstudents.org.uk/advice-and-guidance/promoting-equal-

opportunities/access-and-participation-plans/ (Accessed: 30 June 2020).

Palmer, M.S., Bach, D.J. and Streifer, A.C. (2014) 'Measuring the promise: A LearningFocused Syllabus Rubric'. Journal of Educational Development, 33(1), 14-36. Available at: https://onlinelibrary.wiley.com/doi/abs/10.1002/tia2.20004 (Accessed: 30 April 2020).

Pickford, R. (2016) 'Student Engagement: Body, Mind and Heart - A Proposal for an Embedded Multi-Dimensional Student Engagement Framework.' Journal of Perspectives in Applied Academic Practice, 4(2). ISSN 2051-9788. Available at:

https://doi.org/10.14297/jpaap.v4i2.198 (Accessed: 11 April 2020).

Pickford, R. (2018) 'A Blueprint for Teaching Excellence.' Journal of Perspectives in Applied Academic Practice, 6(1) ISSN 2051-9788. Available at:

https://jpaap.napier.ac.uk/index.php/JPAAP/article/view/299 (Accessed: 30 April 2020).

Pilkington, A. (2013) 'The Interacting Dynamics of Institutional Racism in Higher Education.' Race, Ethnicity and Education, 16(2), 225-245. Available at: https://www.tandfonline.com/doi/abs/10.1080/13613324.2011.646255 (Accessed: 10 April 2020).

Saks, A.M. (2006) 'Antecedents and consequences of employee engagement.' Journal of Managerial Psychology, 21(6), 600-619. Available at:

https://www.researchgate.net/publication/275714108 Antecedents and Consequences of Employee Engagement (Accessed: 30 April 2020).

Salkind, N. (2008) 'Cultural Deficit Model.' In: Encyclopaedia of Educational Psychology. SAGE Publications Inc: Thousand Oaks, CA: Available at: http://sk.sagepub.com/reference/educationalpsychology/n60.xml (Accessed: 29 April 2020).

Sian, K. (2017) 'Being Black in a White World: Understanding Racism.' International Journal for Collective Identity Research. 176. ISSN: 1695-6494. Available at: https://doi.org/10.1387/pceic. 17625 (Accessed: 29 April 2020). 
Smith, S,V, (2017) 'Exploring the BME student attainment gap: What Did It Tell Us? Actions to Address Home Black and Minority Ethnic (BME) Undergraduate Students' Degree Attainment.' Journal of Perspectives in Applied Academic Practice, 5(1), 48-57. ISSN 20519788 Available at: https://jpaap.napier.ac.uk/index.php/JPAAP/article/view/239/pdf (Accessed: 2 February 2020).

Smith, S. (2018) 'The Experience of Commuting and Living at Home: How Does It Affect the Engagement of BME Students with the University and Their Learning.' Journal of Educational Innovation, Partnership and Change. Volume 4, no 1, 1-14. Available at: https://journals.studentengagement.org.uk/index.php/studentchangeagents/article/view/5 20/pdf (Accessed: 29 April 2020).

SOAS (2018) 'Decolonising SOAS Learning and Teaching Toolkit for Programme and Module Convenors.' University of London. Available at:

https://blogs.soas.ac.uk/decolonisingsoas/files/2018/10/Decolonising-SOAS-Learning-andTeaching-Toolkit-AB.pdf (Accessed: 12 May 2020).

Stevenson, J. (2012) 'Black and Minority Ethnic Student Degree Retention and Attainment.' Higher Education Academy. Available at: https://s3.eu-west-

2.amazonaws.com/assets.creode.advancehe-documentmanager/documents/hea/private/bme summit final report 1568036653.pdf (Accessed: 5 April 2020).

Sue, D.W., Capodilupo C.M., Torino G.C., Bucceri, J., Holder, A., Nadal, K. and Esquilin, M. (2007) 'Racial Microaggressions in Everyday Life: Implications for Clinical Practice.' The American Psychologist. Available at: https://www.ncbi.nlm.nih.gov/pubmed/17516773 (Accessed: 16 April 2020).

Thomas, L. and Jones, R. (2017) 'Student Engagement in the Context of Commuter Students.' London: TSEP. Available at:

https://lizthomasassociates.co.uk/projects/2018/Commuter\%20student\%20engagement.pdf (Accessed: 20 April 2020).

Thomas, E and May, H. (2010) 'Inclusive Learning and Teaching in Higher Education.' Report, Higher Education Academy. Available at: https://www.lboro.ac.uk/media/wwwlboroacuk/external/content/services/cap/downloads/docu ments/HEA\%20Report\%20on\%20inclusive\%20teaching.pdf (Accessed: 29 April 2020).

Tovar, E. (2013) 'A Conceptual Model on the Impact of Mattering, Sense of Belonging, Engagement/Involvement, and Socio-Academic Integrative Experiences on Community College Students' Intent to Persist.' CGU Theses and Dissertations. Available at: https://scholarship.claremont.edu/cgi/viewcontent.cgi?article=1083\&amp;context=cgu etd (Accessed: 30 May 2020).

UCL (2018) Inclusive Curriculum Healthcheck. University College London. Available at: https://www.ucl.ac.uk/teaching-learning/sites/teachinglearning/files/ucl inclusive curriculum healthcheck 2018.pdf (Accessed: 29 April 2020). 
UK QUALITY CODE FOR HIGHER EDUCATION (2018) Available at:

https://www.qaa.ac.uk/quality-code (Accessed: 29 April 2020.

Woodyatt, L. and Brooker, A. (2019) 'Student Success: Special Issue: Psychological Wellbeing and Distress in Higher Education.' Student Success, 10(3). Available at: https://studentsuccessjournal.org/article/view/1419 (Accessed :29 April 2020). 